\title{
Disability, Social Policy and the Burden of Disease: Creating an "Assertive” Community Mental Health System in New York
}

\author{
Mark B. Borg, Jr.
}

Community Consulting Group, New York, USA.

Email: oedtrex@aol.com

Received March 24 ${ }^{\text {th }}, 2010$; revised May $11^{\text {th }}, 2010$; accepted May $13^{\text {th }}, 2010$.

\begin{abstract}
One conclusion of the decade-long epidemiological Global Burden of Disease Project is that five of the top 10 disease "burdens" the world will face by 2020 will be related to mental disabilities. Therefore, developing social policy and community responses to the ways that people with mental disabilities are treated is becoming an important focus for community practitioners, political activists and legislators. The author explores some of the dynamics of our culture's approach to dealing with difference, especially when manifested in disenfranchized individuals. He discusses a community development project created by a New York City advocacy and social policy organization following the 1999 murder of a woman by an individual whose mental health disability was never treated. Parallels are drawn between the civil rights and community mental health movements, which created a precedent for the 1990 Americans with Disabilities Act. Also examined are the ways in which community mental health systems manifest social policy that alternately resists, repeats and colludes with power operations. The unexamined assumptions that drive this dynamic are examined as ableism or disability oppression.
\end{abstract}

Keywords: Ableism, Assertive Community Treatment, Civil Rights, Disability, Kendra's Law

\section{Introduction}

Over the last century, the pace of urbanization and industrialization in the West has outstripped the development of certain life-sustaining infrastructures that support urban residents. We in the United States are now witnessing a backlash wherein deindustrialization, corporate downsizing, unemployment and the dismantling of the welfare state are adding to the already considerable pressure on our support structures [1,2] and, in turn, on the legislation and social policies that address these structures [3-5]. Epidemiological studies are showing that exponential growth in urbanization and industrialization and their decompensatory effects are resulting in increasing numbers of physical and mental health impairments [6]. Researchers working on the Global Burden of Disease Project (GBD) have used a measure they call disease burden to project future causes of deaths and impairments $[7,8]$. They believe that by 2020 , the leading causes will be heart disease, depression and traffic accidents (Murray and Lopez, 1996, 2004). Furthermore, they predict, along with other researchers [9-11], that five of the top 10 leading causes of "disease burden" by 2020 will be "psychiatric conditions." If that is accurate, it is imperative that we evaluate our service provision infrastructure for these conditions, the social policies that support it and the cultural and political implications of such services. These implications include oppression and social injustice in the institutions we create to address our growing burden of psychiatric disease.

I spent four years on the executive board of a community health center in New York City, observing and participating in an effort to develop an effective philosophy and infrastructure for current conditions in the city. In particular, we focused on the changes in social policy that would be necessary to address the needs of our patient population. Over the same period, I also worked with a community development project managed by the Coalition of Voluntary Mental Health Agencies, a social policy and advocacy organization representing over 100 nonprofit community mental health agencies in New York City. These experiences illuminated important intersections and parallels between the civil rights and community mental health movements, and demonstrated 
clearly how the two earlier movements created precedents for the Americans with Disabilities Act (ADA).

I will explore how the philosophies underlying these movements both have and have not been enacted in contemporary social policy in the U.S., and how their backgrounds offer insight into the history, development and policies of New York's current community mental health system. Specifically, I will examine 1) how this system and its social policies are bound by their own history, operational methods and current problems; and 2) how the system's social policy alternately resists, repeats and colludes with power operations - that is, how policies often cause the system to act against its ostensible goal. The unexamined assumptions that drive this dynamic have been called ableism or disability oppression [12]. These terms refer to institutional discrimination that excludes individuals with physical and mental disabilities from full participation in society.

The primary task of the community mental health system, in general, is to take responsibility for the health and well-being of people deemed incapable of taking care of themselves. Included in this responsibility is the behavior of such individuals in their communities. I will describe a major breakdown that occurred in the New York City community mental health system in 1999 and the policy changes that were enacted in response.

Of course, the primary task I have sketched above is by definition problematic, since it entails a dynamic that supports disempowerment and chronic dependency in the individuals who use it. It also supports the maintenance of power and control over people who rely on their mentally ill or disabled status to ensure that their physical and mental health needs are addressed and paid for. From this perspective, the concept of impairment is kept separate from expressions of injustice resulting from social, economic and political arrangements [13]. This is a particularly harmful situation in light of the many impairment etiologies that have been "manufactured" and sustained by such arrangements $[4,14,15]$.

\section{Civil Rights, Oppression, and the Americans with Disabilities Act (ADA)}

In the 1960s, the American civil rights movement finally succeeded in getting the U.S. Congress to pass legislation banning discrimination based on sex, race and national origin. The original laws did not include protection against discrimination based on physical and/or mental disabilities. However, people with disabilities quickly realized that their positions and needs mirrored the racial-, ethnic- and gender-based exclusions and discriminations that were now receiving legal protection.

In 1971, disability advocates convinced several Congressional lawmakers to introduce an amendment to Title VI of the Civil Rights Act of 1964 that would prohibit discrimination based on physical or mental disabilities. This bill died in committee, as did a 1972 bill addressing employment discrimination for people with disabilities. Both failures reflected the lack of concern of most lawmakers, and many Americans, for the civil rights of persons with disabilities [16]. These individuals were not considered a "class" worthy of protection until the Rehabilitation Act of 1973 was passed and signed into law. That law encouraged disabled populations to see themselves as oppressed minorities with agendas to present to the American people-a new kind of thinking. The grassroots movement that grew from this initial spark lobbied for the Americans with Disabilities Act (ADA), which was passed in 1990. The ADA gave substantial recognition to the difficulties of individuals with disabilities who must navigate their way through a society tailored to the needs of able-bodied persons.

According to the ADA, a disability is interpreted as 1) any physical or mental impairment that substantially limits one or more of an individual's major life activities; 2) a record of such an impairment; or 3) someone regarded as having such an impairment [17]. This definition individualizes the experience of disability, on the grounds that generalized responses and acts of assistance may not be adequate to provide opportunities for the larger disabled population. That stance-commonly referred to as disability oppression theory-advocates responses based on individual needs. In contrast, ableistic ideologies advocate "fixing" or "correcting" disabled individuals so that they match standard system designs. Casteneda and Peters have noted that "disability oppression theory insists on the culpability of society's inhibiting structures, which overvalue economic productivity, undervalue alternative social contributions and attach positive and negative associations to relative forms of independence and dependence" [12].

All laws providing educational and rehabilitation services and prohibiting discrimination in education, employment and access to public programs emphasize similarities in needs and problems within an array of physical, psychological and intellectual impairments. Laws are unlikely to acknowledge differences among disabling conditions and their varied impacts on people's lives. Most importantly, social policy and the programs designed to serve the multifaceted "groups" we call "disabled" are based on an assumption that invites challenge: that any disability is the primary variable that predicts the outcome of social interaction and program success. In fact, it is social context that generally shapes the meaning of a person's disability.

This means that social policy and related interventions would often do better to target the disabling environment instead of the individual disabilities [18]. To the extent that Americans resist laws supporting the civil rights of people with disabilities, we could argue that our entire 
society is a disabling environment. However, it may be more fruitful to address these issues on a smaller scalein the context of the system designed to serve people with mental disabilities.

\section{Point of Impact}

The current policy of deinstitutionalizing mentally ill individuals in the U.S. was 50 years in the making. The combined population of residents in state and county mental hospitals in this country has dropped from more than 500,000 in 1950 to approximately 50,000 in more current times $[19,20]$. However, the total population of mentally disabled prison inmates has increased to the point that a person with a serious mental illness is almost five times as likely to be incarcerated than admitted to a psychiatric care facility. And a similar pattern seems to underscore the Crime and Disorder Act (1998) in the U.K. [21,22].

This juxtaposition of declining treatment and increasing incarceration rates has attracted considerable attention from deinstitutionalization critics, who note that most governments have consistently failed to establish promised community-based treatment programs [23]. However, there are signs that the tide is turning. Backed by research asserting that treatment can reduce violence in people with major psychiatric disorders, and by high-profile cases of violent crimes committed by people suffering from severe mental illness, community-based treatment approaches are slowly gaining attention in this drama $[24,25]$. The issue remains controversial, since it pits public safety concerns against individual rights.

Occasionally some specific incident becomes a symbol/symptom of chronic malfunction in a system. I call such occurrences points of impact [26-30]. A point of impact is an acute symptom that makes manifest a more chronic community crisis. Civil unrest is an examplethat is, the civil unrest is the force, and the crisis to which it is applied is the point of impact. A point of impact-or the collision that it indicates-occurred in New York in 1999, and brought into public awareness the chronic state of crisis in the city's community mental health system. In hindsight, we can view the event as support for the GBD project's prediction.

In January of that year, a 30-year-old man with schizophrenia named Andrew Goldstein pushed 32- yearold Kendra Webdale in front of a Manhattan subway train moving at full speed. Goldstein was subsequently convicted of second-degree murder. The murder incited public outrage that was translated into "Kendra's Law" - a requirement for forced treatment (sometimes called "assisted outpatient treatment") for people with severe mental illness. Prior to the killing, Mr. Goldstein had made repeated requests for treatment but had been denied each time. Yet the State of New York, which described
Mr. Goldstein as mentally ill when Kendra's Law was being written and debated, argued in court that he was sane when he pushed Ms. Webdale in front of the train. A final irony is that Mr. Goldstein, as a convicted murderer, is only now receiving the treatment that he had previously been refused. It is a decade later, and the policies and approaches to treatment seem to merely repeat this pattern-even more so now with the closing and impending closing of major inner-city hospitals like Cabrini-ad infinitum. What are the dynamics of a culture that implements such policies as the ones institutionalized in Kendra's Law?

\section{Liberal Individualism and a Culture of Ruthless Discrimination}

Western societies in general seem to be breeding pools for the development and proliferation of remediessocial, personal, and cultural-for just about anything that might cause discomfort. These remedies notably target pain and anxiety, and also their derivatives: irritation, frustration, sadness, anger and so on. Paradoxically, however, they also serve to marginalize individuals in categories (such as "mentally disabled") who cause such feelings to arise within members of the majority group. A further paradox is that while palliative remedies such as these reduce pain and suffering, they destroy the opportunity to study and treat definitively, and eventually recover from, the problems that underlie the unpleasant symptoms [28]. Palliative remedies help individual members of society to dissociate our awareness of the suffering of others around us. They encourage, that is, a kind of ruthlessness that eventuates in discrimination against various minority groups and their members. On this subject I have previously written that:

Human - that is, emotional-responses to everyday stimuli are increasingly pathologized, and we are increasingly promised the obliteration of all personal suffering. Yet at the core of all these human responses to suffering that need remedy is a deep sense of empathy with the struggles of existing at this time in this society, in a state of perpetual dread over the immense social problems that infect those around us, and that seem (and often are) insurmountable [28, emphasis in original].

Certain kinds of empathy are feared, defended against and abstained from in this society, as if compassion - the ability to experience the pain and problematic circumstance of another person-were a contagion that if experienced in full force would lead to breakdown. One of these is empathy for those whom we view (and scapegoat) as carriers of manifest social pathology. Legislation like "Kendra's Law" encourages us to dissociate the suffering of such people and impose constraints upon them instead.

The general American movement toward liberal individualism as described in the sociological analyses of 
Bellah, Madsen, Sullivan, Swindler and Tipton [31] supports the Kendra's Law mentality. Bellah and colleagues asserted that the definitive aim of life in a liberal, individualistic society is to promote fulfillment (increased satisfaction and decreased discomfort) for individuals, rather than groups or communities. By individualizing fulfillment and satisfaction, people in such cultures are perfectly set up to ignore and are supported in the practice of ignoring, or dissociating the suffering of others. That is, enacting a ruthless discrimination as a status quo approach to living, making massive categorical biases seem necessary. The underside of the argument presented by Bellah and others, such as Amitai Etzioni [32] is that such arguments pose a kind of "new communitarianism" that defines community as prior to individual rights and a call for a return to traditional social institutions such as religion and the family $[33,34]$. The new communitarians largely uphold the liberal Western tradition, criticizing deviations or threats to this tradition [35]. Yet in this process, they wind up repeating the elitist underpinning of the very system they criticize, and becoming the watchdogs of their own version of the "good life." The pervasiveness of the liberal individualism perspective has been analyzed in many of the social and cultural institutions in capitalist societies, particularly the United States. The mental health machinery of this country has attracted special interest [36,37]. In fact, some authors have specified a sense that the ways in which the major critiques of liberal individualism themselves have been framed supports a kind of "America as Empire" philosophy [38-40] that overlooks crucial issues related to race, class and gender bias [1,41-43] as well as ableism.

The dynamics of discrimination that underlie liberal individualism can be seen as a societal-level character defense that allows us to avoid acknowledging the social consequences of a belief system that supports fulfillment for some and suffering for others. As this belief system rigidifies, it begins to function as an ideology. By ideology I mean "those values and assumptions about the world which have implications for the control and allocation of limited resources" [44]. Problems and fulfillments are increasingly individualized, separated from their social and cultural influences and etiologies, and the resulting control and allocation processes are dissociated $[2,45]$. The inability or unwillingness to empathize with both self and other diminishes the likelihood that subversive or revolutionary processes will exert any impact on society's daily functions, let alone accomplish any significant social transformations.

When (individual, group or community) awareness of pain and suffering is reduced through the use of sanctioned group-level discrimination, what remains is a form of chronic crisis so muffled that even those in the middle of it may not perceive it. This process not only supports a "victim-blaming ideology" [46]. It also establishes a framework for defining social problems in terms of social conditions (e.g., poverty, racism, poor healthcare) and the groups that allegedly engender them $[47,48]$. The dynamics of ruthlessness concretize the split between the subjectified self and the objectified (or "inanimate") other $[13,49,50]$. I will now discuss an ongoing social justice project that has attempted to address some of the underlying problems associated with these dynamics.

\section{Community Response and the Development of a Responsive Social Policy}

The Coalition of Voluntary Mental Health Agencies (the Coalition) considers that its primary task is to ensure that New York's community mental health care system provides adequate care for the people it is meant to serve. The Coalition's member agencies serve more than 250,000 clients in almost all the communities and neighborhoods of our country's most diverse city.

The Coalition is a child of deinstitutionalization. New York State began its deinstitutionalization program in part because advocates and policy makers recognized that people with mental illness deserved better than to languish in huge, impersonal hospitals. Deinstitutionalization implied not only fiscal savings, but also a promise — still unfulfilled - that clients discharged from psychiatric hospitals would receive adequate care upon their return to their communities. The Coalition was born to address the failure of communities to provide that care.

Toward the end of January 1999, the Coalition held a meeting to address the issues raised by the Webdale/ Goldstein tragedy. Its spokesperson and executive director, Phillip Saperia, claimed that:

For Andrew Goldstein, it seems we traded a huge state hospital for an $8 \times 10$ basement room along with alternating hospital readmission and outpatient clinic treatment. Andrew is not blameless in this tragedy, but neither is the State of New York. This was not, as some have suggested, an act so random as to be unavoidable. While we cannot prevent every tragedy, we know how to guard against catastrophes like this one. We know that integrated, assertive, coordinated community-based treatment works. We know that discharging someone from a hospital without a discharge plan to a lonely basement apartment with little professional support, onsite services or crisis intervention does not work [51].

The Webdale/Goldstein tragedy is but one of the cases the Coalition has used to shed light on critical issues affecting adequate treatment, service delivery and policy for people with mental disabilities. The Coalition serves as a vocal advocate for adequate care and the realistic resources - especially legislative - required to provide it. Funding is a major community mental health service issue in New York State, as it is throughout the country; 
this is the issue that the Coalition addresses most consistently. Currently the Coalition is confronting cuts in Medicaid and Medicare funding, the movement toward managed care, and the ways that these trends keep the people in their population from enacting their own treatment programs.

The Coalition is struggling to become a more responsive and collaborative organization, willing to engage in necessary self-confrontation and self-critique. Collaboration among its own members and with members of the client population has raised the possibility that the central task of the community mental health system is inherently problematic. That is, to take uncritical responsibility for the health and well-being of people deemed incapable of taking care of themselves sets up endless opportunities for oppressive, colonizing, disempowering and iatrogenic treatment patterns and legislation. The Coalition recognizes that the voices, experiences and insights of those being served must be included when service delivery programs are being developed [52,53]. Since the most successful action plans are developed collaboratively with the clients being served [51], the Coalition is now calling its clients "consumers"-an indication of empowerment and entitlement to make choices about what constitutes adequate care.

This right is clearly challenged by Kendra's Law. Over the last few years, Coalition members have been working with local and state officials (as well as with clients) to develop more appropriate intervention and policy responses to such system failures as the Webdale/Goldstein tragedy. Its goal has been to account for the safety and security needs of both clients and communities, while preserving the right of people with mental health disabilities to be treated in humane ways.

\section{Assertive Community Response}

Deinstitutionalization began with the closure of many long-term state and private hospitals. It coincided with the introduction of new pharmacological treatments. Since the 1950s, when the process began, there has been ongoing concern about providing care for the most seriously ill patients. In many cases, the multifaceted and complex psychosocial needs of the mentally ill living in local communities were not adequately addressed. Efforts at rehabilitation were at best partially effective, if at all. This policy failure has been attributed to such factors as underfunding, new challenges (e.g., rampant substance abuse) and high rates of noncompliance with medication regimens and treatment programs [54-56].

The Assertive Community Treatment model was created in the 1970s by a Wisconsin mental health team to address policy and implementation issues in a proactive and comprehensive manner [25]. And there has been an ongoing attempt to create a responsive community men- tal health policy and delivery system. New York State's Assertive Community Treatment (ACT) program, started in 2003 as a belated response to the Webdale/Goldstein tragedy, was born out of collaboration among various community mental health agencies and clients. Observers have noted that there were numerous pleas from the Coalition to start an ACT program well before the murder. Yet it is only recently that ACT has been regularly used as a middle ground between policies of either forced or no treatment for patients experiencing more acute manifestations of mental disability $[51,57,58]$. Offshoot projects such as the Collaborative Mental Health Initiative have also been created to implement policy and programs that acknowledge and respond to the experiences and needs of the mentally disabled.

To help clients achieve meaningful goals, ACT has accepted a consumer-centered approach to its policies and efforts, very much in contrast to programs based on institutional structures (e.g., homeless shelters, detoxification centers). Goals are expressed in terms of vocational achievement, adequate housing and interpersonal relationships.

Central ACT criteria include:

1) Provision of targeted services to the severely mentally ill;

2) Provision of direct services through treatment teams rather than outside clinicians;

3) A small staff-to-client ratio (1:10 or less);

4) Shared team responsibilities so that clients receive attention from multiple staff members;

5) Individualized treatment and support;

6) Comprehensive and flexible services;

7) Administration of most treatments and services outside of clinical settings;

8) No time limit on services;

9) Service delivery 24 hours/7 days per week; and

10) Focus on patients' individual strengths and needs.

Based on innovative and responsive developments in the realm of social policy, ACT teams deliver flexible treatment, rehabilitation, case management and support services to individuals with mental illness whose needs have not been adequately met by traditional service delivery approaches. According to Herinckx et al. [59], the results of approximately 25 controlled trials have demonstrated the clinical- and cost-effectiveness of the ACT program. Although evidence-based practices are helpful in terms of program quality, their uniform standards frequently overlook local needs and variations. Thus, too much fidelity to structure can diminish the creativity that ACT requires to evolve and maintain its effectiveness.

\section{Ongoing Development of Social Policy and Community Treatment}

The fight for civil rights is an ongoing struggle on the part of any groups oppressed by institutions and ideolo- 
gies that ignore unique histories, cultural formations, individual and family identities, and the needs of those groups to be adequately represented within a daily societal context. Since the beginning of the civil rights movement, middle-class values clearly legitimate and regulate the cultural hierarchies that demean marginalized groups and reinforce racial, economic and ableistic inequalities - often reflected in the very legislation that targets their struggles. Since the civil rights movement began, middle-class values have been at the top of the cultural hierarchy that dictates and validates the legislation that targets marginalized groups, so that demeaning racial, economic and ableistic inequalities may be reinforced by the same legislation that purports to remedy them. In the struggle for equality, the institutional forms of domination that affect the lives of the disabled cannot be separated from the cultural ones. It should come as no surprise, to anyone familiar with civil rights movement history, that the same dynamics that all historically oppressed groups play out continue within the policies and interventions aimed at individuals with mental and physical disabilities.

Treating mentally ill people without their consent is currently the most contested human rights issue in mental health law and policy. Although 40 jurisdictions in the U.S. have statutes nominally authorizing outpatient commitment (in other words, legal orders to adhere to prescribed community treatment), until recently only a few states have vigorously promoted and enforced such laws [23,55]. National interest in outpatient commitment soared with Kendra's Law and the 2003 enactment of "Laura's Law" in California—also named after a young woman killed by a mentally ill person who had not received treatment. Many states are now involved in an emotionally charged, take-no-prisoners battle between advocates of "assisted treatment" (the term preferred by proponents of outpatient commitment) and advocates of "leash laws" (a less flattering term).

Almost every American community has a subpopulation of mentally ill individuals who interact with public agencies and institutions-public housing authorities, social welfare agencies, community mental health centers, public hospitals, substance abuse programs, police departments, courts and the prisons. The increasing number of these people-often labeled "revolving-door patients" - has been attributed variously to more restrictive criteria for involuntary commitment, the limited availability of effective inpatient care, a paucity of effective community-based services and a lack of community support programs $[8,60,61]$, as well as, more recently, the impact of trauma for veterans of the war in Iraq [62]. This population would benefit from responsive legislation built on, and sustained in part by, input from its beneficiaries.

There has always been a fine line between assertive help-giving practices and oppressive tendencies in this country's mental health delivery system-especially in large urban centers such as New York City. The effort to create responsive social policies to address the community mental health system - that simultaneously contain the potential for violence and disorder and effectively address the burdensome needs of the mentally disabledis a narrative of one hand giving and the other taking away. That is, mid- $19^{\text {th }}$ century incarceration followed by early- $20^{\text {th }}$ century institutionalization, followed by late$20^{\text {th }}$ century deinstitutionalization mandated recapture (e.g., Kendra's Law) and currently a collaborative approach that includes the voices of "consumers" in such programs as ACT.

The central point of this narrative is an area often overlooked by social justice and cultural theorists; even those who effectively address oppression and discrimination issues along race, class and gender lines. When ableism drives interventions for "social justice"-especiallly for people oppressed and discriminated against for mental disabilities - the contradictions it brings with it are seldom noticed. With a few notable exceptions [e.g., 63-65], the invisibility of the conflict means that social justice discourse (and the social policies it stimulates) do not consider how race, class, gender and sexual orientation issues are also part of the disabled population equation. That oversight then reinforces oppressive and discriminatory practices against the disabled in the very social institutions and policies meant to serve them.

\section{Conclusions}

As long as we live in a culture that develops and implements repressive social policies, we are all culpable for the oppressive behaviors that such policies support. Don DeLillo speaks to this point in his novel The Names, when he writes that "Those who engaged knowingly were less guilty than the people who carried out their designs. The unwitting would be left to ponder the consequences, to work out the precise distinctions involved, the edges of culpability and regret” [66]. Our attempts to redress discrimination are shaped by the very philosophies that cause the discrimination in the first place- the philosophies that exist both to embody and contain our anxieties about frightening social problems, and to unburden us from those anxieties.

Researchers in the Global Burden of Disease Project (GBD) have predicted that by 2020, five of the top 10 "disease burdens" the world will be addressing will be related to mental disabilities [8,67]. Even in an organization like GBD, this is an unfortunate lumping together of mental disability categories; it reduces them to a societal burden as the ableistic and other discriminatory practices do and perpetuates the use of disabled people as scapegoats for societal malfunctions. Reductionistic appro- 
aches to people with mental illness-approaches that ignore the facts of complex circumstances, multiple identities, various etiologies and personal struggles-make them easy targets for fearful projections (e.g., breakdowns, violence, instability) within the general population. In its worst form, this process represents a "victim-blaming ideology" [46] that casts doubts on the legitimate rights of oppressed groups and supports cutbacks in, or the elimination of, institutions meant to provide services for them.

Henry Giroux argues that "Domination is never total in its effects; contradictions arise within all public spaces, even those that appear most oppressive" [42]. It seems as though the further we move from social investment, the closer we come to policies of social domination or containment in which state services are reduced to the repressive functions of discipline, control and surveillance [6,45,68-72]. One important focus for challenging the effects of this kind of domination is the creation of responsive communities and policies that can address the unique circumstances of individuals in need of mental health services.

The ACT program and offshoot projects such as the Collaborative Mental Health Initiative exemplify how it is possible to address the needs of groups too frequently overlooked in social justice discourses. When we look beyond the language of individual pathology to the more threatening issue of how we treat marginalized populations, we expose frighteningly the degree to which many people in this society still lack the security and resources they need for safety, empowerment and well-being.

\section{REFERENCES}

[1] H. Giroux, "The Abandoned Generation: Democracy beyond the Culture of Fear,” Palgrave Macmillan, New York, 2003.

[2] S. Zizek, “Organs without Bodies,” Routledge, New York, 2004.

[3] N. Gilbert and A. Etzioni, "Transformation of the Welfare State,” Oxford University Press, 2002.

[4] E. Huber and J. D. Stephens, "Development and Crisis in the Welfare State,” University of Chicago Press, 2001.

[5] D. Swank, "Global Capital, Political Institutions, and Policy Change in Developed Welfare Nations," Cambridge University Press, Cambridge, 2002.

[6] A. Price-Smith, "Plague and Politics: Disease and International Policy,” Palgrave Macmillan, New York, 2001.

[7] C. D. Mathers and D. Loncar, "Projections of Global Mortality and Burden of Disease from 2002 to 2030," PLoS Medicine, Vol. 3, No. 11, 2006, p. e442.

[8] World Health Organization, "Primary Health Care: Now More than Ever," World Health Organization, Geneva, Switzerland, 2008.
[9] P. Duckett, “It’s War, and It’s Official: Repositioning Impairment and Disability into the Society for Community Research and Action,” The Community Psychologist, Vol. 37, 2004, pp. 10-14.

[10] J. A. Haagsma, A. H. Haavelar, M. F. Janssen and G. J. Bonsel, "Disability Adjusted Life Years and Minimal Disease: Application of a Preference-Based Relevance Criterion to Rank Enteric Pathogens,” Population Health Metrics, Vol. 6, 2008, pp. 345-368.

[11] K. Lee, "Health Impacts of Globalization," Palgrave Macmillan, New York, 2003.

[12] R. Casteneda and M. Peters, “Ableism,” In: M. Adams, W. J. Blumenfeld, R. Castaneda, H. W. Hackman, M. Peters and X. Zuniga, Eds., Reading for Diversity and Social Justice: An Anthology on Racism, Antisemitism, Sexism, Heterosexism, Ableism, and Classism, Routledge, New York, 2000, pp. 310-325.

[13] D. Blackwell, "Colonialism and Globalization: A GroupAnalytic Perspective,” Group Analysis, Vol. 36, No. 4, 2003, pp. 445-464.

[14] P. Abberley, "The Concept of Oppression and the Development of a Social Theory of Disability," Disability, Handicap and Society, Vol. 2, No. 1, 1987, pp. 5-20.

[15] D. Ferguson and S. Taylor, "Interpreting Disability," Teachers College Press, New York, 1992.

[16] S. Stefan, "Unequal Rights: Discrimination against People with Mental Disabilities and the Americans with Disabilities Act," American Psychological Association, Washington, DC, 2001.

[17] United States Department of Justice, “ADA Legal Documents: Public Law 101-336,” U.S. Department of Justice, Washington, DC, 1999.

[18] J. Swan, S. French and C. Cameron, "Controversial Issues in a Disabling Society,” Open Universities Press, Buckingham, 2003.

[19] J. Monahan, M. Swartz and R. J. Bonnie, "Mandated Treatment in the Community for People with Mental Disorders," Health Affairs, Vol. 22, No. 5, 2003, pp. 28- 38.

[20] K. H. Shelton, P. J. Taylor and M. van den Bree, "Risk Factors for Homelessness: Evidence from a PopulationBased Study,” Psychiatric Services, Vol. 60, No. 4, 2009, pp. 465-472.

[21] A. Barton, "Sentenced to Treatment: Criminal Justice Orders and the Health Service," Critical Social Policy, Vol. 19, No. 4, 1999, pp. 463-483.

[22] A. Bradley, “Treatment and Testing Orders,” Criminal Justice Matters, Vol. 31, 1998, pp. 21-34.

[23] J. Swanson, "Psychiatric Advance Directives: An Alternative to Coercive Treatment?” Psychiatry, Vol. 63, No. 2, 2000, pp. 160-172.

[24] M. Perlin, “The Hidden Prejudice: Mental Disorder on Trial,” American Psychological Association, Washington, DC, 2000.

[25] J. Swanson, "Three Risk Factors Cited in Violent Behavior among People with Severe Mental Illness,” American 
Journal of Public Health, Vol. 92, 2003, pp. 1523-1531.

[26] M. B. Borg, Jr., “The Avalon Gardens Men’s Association: A Community Health Psychology Case Study,” Journal of Health Psychology, Vol. 7, No. 3, 2002, pp. 345-357.

[27] M. B. Borg, Jr., "Venturing beyond the Consulting Room: Psychoanalysis in Community Crisis Intervention," Contemporary Psychoanalysis, Vol. 40, No. 2, 2004, pp. 147174.

[28] M. B. Borg, Jr., “A Zombie Storms the Meathouse: Approximating Living and Undergoing Psychoanalysis in a Palliative Care Culture," Psychoanalysis, Culture and Society, Vol. 9, 2005, pp. 212-233.

[29] M. B. Borg, Jr., “Community Psychoanalysis: Developing a Model of Psychoanalytically-Informed Community Crisis Intervention,” In: N. Lange and M. Wagner, Eds., Community psychology: New Directions, Nova Science Publishers, Happague, 2010, pp. 1-66.

[30] M. B. Borg, Jr., E. Garrod, M. R. Dalla and J. McCarroll, "Can Psychoanalysis Exist outside the Consulting Room? In: B. Willock, R. Curtis and L. Bohm, Eds., Taboo or not Taboo: Forbidden Thoughts, Forbidden Acts in Psychoanalysis, International Universities Press, Madison, 2009, pp. 193-207.

[31] R. Bellah, R. Madsen, W. Sullivan, A. Swindler and S. Tipton, "Habits of the Heart: Individualism and Commitment in America," University of California Press, Berkeley, 1985.

[32] A. Etzioni, “A Responsive Society,” Jossey-Bass, San Francisco, 1991.

[33] D. Bell, “The Cultural Wars: American Intellectual Life,” Wilson Quarterly, Summer 1992, pp. 74-107.

[34] A. Samuels, "Politics on the Couch: Citizenship and the Internal Life,” Karnac, New York, 2001.

[35] N. Ellin, "Postmodern Urbanism," Princeton Architectural Press, New York, 1999.

[36] F. Richardson, B. Fowers and C. Guignon, "Re-envisioning Psychology: Moral Dimensions of Theory and Practice,” Jossey-Bass, San Francisco, 1999.

[37] C. Taylor, "The Ethics of Authenticity,” Harvard University Press, Cambridge, 1992.

[38] S. Clarke and P. Hoggett, "The Empire of Fear: American Political Psyche and the Culture of Paranoia," Psychodynamic Practice, Vol. 10, No. 1, 2004, pp. 89-106.

[39] J. Garrison, “America as Empire: Global Leader or Rogue Power?” Berrett-Koehler, San Francisco, 2004.

[40] C. Johnson, "The Sorrows of Empire: Militarism, Secrecy, and the End of the Republic,” Metropolitan Books, New York, 2004.

[41] S. Clarke, "Social Theory, Psychoanalysis and Racism," Palgrave Macmillan, New York, 2004.

[42] H. Giroux, "Stealing Innocence: Corporate Culture’s War on Children,” Palgrave Macmillan, New York, 2000, p. 69.

[43] A. Schultheis, "Regenerative Fictions: Postcolonialism,
Psychoanalysis and the Nation as Family," Palgrave Macmillan, New York, 2004.

[44] G. W. Knox, “An Introduction to Gangs,” Wyndham Hall Press, Bristol, 1995, p. 3.

[45] E. Said, “Culture and Imperialism,” Alfred A. Knopf, Inc, New York, 1993.

[46] W. Ryan, "Blaming the Victim," Vintage, New York, 1971.

[47] E. Seidman and J. Rappaport, "Redefining Social Problems,” Plenum, New York, 1986.

[48] M. R. Warren, "Dry Bones Rattling: Community Building to Revitalize American Democracy,” Princeton University Press, Princeton, NJ, 2001.

[49] F. Fanon, "The Wretched of the Earth," Grove, New York, 1068.

[50] P. Freire, "Pedagogy of the Oppressed," Continuum, New York, 1970.

[51] P. Saperia, "Hearing on Oversight: Supervision of Outpatient Mental Health Services," Coalition of Voluntary Mental Health Agencies, New York, 1999, p. 3.

[52] J. G. Bock, "Towards Participatory Community Appraisal," Community Development Journal, Vol. 36, No. 2, 2001, pp. 146-153.

[53] M. Swartz, J. Swanson and J. Monahan, "Endorsement of Personal Benefit of Outpatient Commitment among Persons with Severe Mental Illness,” Psychology, Public Policy, and Law, Vol. 9, No. 1-2, 2003, pp. 70-93.

[54] L. A. Bell, M. Adams and P. Griffin, "Teaching for Diversity and Social Justice,” Routledge, New York, 2007.

[55] M. L. Korn, "Approaches to Assertive Community Treatment,” Medscape, 2004. http://www.medscape.com/ viewarticle457029

[56] C. Tam and S. Law, "Best Practices: A Systematic Approach to Management of Patients Who Refuse Medications in an Assertive Community Treatment Team Setting,” Psychiatric Services, Vol. 58, No. 4, 2007, pp. 457459.

[57] P. Backlar, "Consumer, Provider, and Informal Caregiver Opinions on Psychiatric Advance Directives," Administration and Policy in Mental Health, Vol. 28, No. 6, 2001, pp. 427-441.

[58] J. S. Lamberti, R. Weisman and D. I. Faden, "Forensic Assertive Community Treatment: Preventing Incarceration of Adults with Severe Mental Illness," Psychiatric Services, Vol. 55, No. 11, 2004, pp. 1285-1293.

[59] H. Herinckx, R. Kinney, G. N. Clarke and R. Paulson, "Assertive Community Treatment Versus Usual Care in Engaging and Retaining Clients with Severe Mental Illness,” Psychiatric Service, Vol. 48, No. 10, 1997, pp. 1297-1306.

[60] R. E. Drake, H. H. Goldman and H. S. Leff, "Implementing Evidence-Based Practices in Routine Mental Health Settings," Psychiatric Services, Vol. 52, No. 2, 2001, pp. 179-182. 
[61] Institute of Medicine, "Envisioning the National Health Care Quality Report," National Academies Press, Washington, DC, 2001.

[62] J. F. McCarthy, M. Valenstein, L. Dixon, S. Visnic, F. C. Blow and E. Slade, "Initiation of Assertive Community Treatment among Veterans with Serious Mental Illness," Psychiatric Services, Vol. 60, No. 2, 2009, pp. 196-201.

[63] C. Liachowitz, "Disability as a Social Construct," University of Philadelphia Press, Philadelphia, 1998.

[64] M. McClintock and L. Rauscher, "Ableism Curriculum Design,” In: M. Adams, L. Bell and P. Griffin, Eds., Teaching for Diversity and Social Justice, Routledge, New York, 2007, pp. 198-229.

[65] T. Shakespeare, "Cultural Representations of Disabled People: Dustbins for Disavowal,” Disability and Society, Vol. 9, No. 3, 1994, pp. 283-300.

[66] D. DeLillo, “The Names,” Alfred A. Knopf, New York, 1982, p. 317.
[67] J. L. Murray and A. D. Lopez, "The Global Burden of Disease: Comprehensive Assessment of Mortality and Disability from Disease, Injuries, and Risk Factors in 1990 and Projected into 2020,” Harvard University Press, Cambridge, 1996.

[68] S. Aronowitz, "The Death and Rebirth of American Radicalism,” Routledge, New York, 1996.

[69] I. Illich, "Medical Nemesis: The Expropriation of Health,” Pantheon, New York, 1976.

[70] M. Foucault, "Discipline and Punish: The Birth of the Prison,” Vintage, New York, 1977.

[71] P. Griffin, H. Steadman and J. Petrila, "The Use of Criminal Charges and Sanctions in Mental Health Courts," Psychiatric Services, Vol. 53, No. 10, 2002, pp. 12851289.

[72] J. L. Murray and A. D. Lopez, "The Global Epidemiology of Noncommunicable Disease,” Harvard University Press, Cambridge, 2004. 